Article

\title{
Prevalence and Correlates of Hopelessness among Turkish Elderly People Living with Family or in Nursing Homes
}

\author{
Ertuğrul Şahin 1,*(D), Nursel Topkaya ${ }^{2}(\mathbb{D})$, Cem Gençoğlu ${ }^{3}$ and Ercümend Ersanlı 4 \\ 1 Department of Guidance and Psychological Counseling, Amasya University, \\ 05100 Amasya Merkez/Amasya, Turkey \\ 2 Department of Guidance and Psychological Counseling, Ondokuz Mayıs University, \\ 55139 Atakum/Samsun, Turkey; nursel.topkaya@omu.edu.tr \\ 3 General Directorate of Basic Education, Ministry of Education, 06650 Ankara, Turkey; \\ cemgencoglu@meb.gov.tr \\ 4 Department of Social Services, Ondokuz Mayıs University, 55139 Samsun, Turkey; eersanli@omu.edu.tr \\ * Correspondence: ertugrulsahin@amasya.edu.tr
}

Received: 23 March 2018; Accepted: 6 June 2018; Published: 8 June 2018

\begin{abstract}
The aim of the current study was to examine the prevalence and socio-demographic correlates of hopelessness among Turkish elderly people. A convenience sample of 100 elderly people (51 women, 49 men) living in a city in the central Black Sea region of Turkey completed the Beck Hopelessness Scale and a data collection instrument to identify their socio-demographic information. The data was analyzed using Chi-Square, Pearson correlation, and hierarchical multiple regression analysis. The study results revealed that $81 \%$ of the elderly, or approximately eight out of 10 elderly people, experience hopelessness, ranging from mild to severe levels, and that severe hopelessness is more prevalent among elderly people living in nursing homes. No gender differences were found in terms of the severity of hopelessness among the elderly. The results of the hierarchical multiple regression analysis also showed that hopelessness scores were positively associated with living in a nursing home, being widowed/a widower, and having a low monthly income. Considering the fact that hopelessness levels are correlated with suicidal thoughts, depression, and adverse health conditions, the mental health professionals who aim to increase the well-being of the elderly should conduct screening studies to determine hopelessness levels among this population. Mental health support is also recommended to increase hope among elderly Turkish people, specifically those living in nursing homes and those who are widowed/widowers and low-income individuals.
\end{abstract}

Keywords: hopelessness; elderly people; correlates; multiple regression analysis; Turkey

\section{Introduction}

The elderly population is increasing all over the world and Turkey is not an exception. Turkey ranks 66th out of 167 in the ranking of the countries with the highest proportion of elderly people. According to the 2015 population census results, $8.2 \%$ of the population of Turkey is composed of elderly people. The growing population of the elderly in the world has led to a number of studies to determine correlates of mental health among the elderly, and the results of these studies have generally shown that this portion of the population faces a number of mental health problems [1,2].

One of the most frequent mental health problems among the elderly is depression, and available evidence consistently suggests that depression is associated with feelings of hopelessness [3,4]. For example, Kim et al. [4] explored the relationship between neuroticism, hopelessness, and depression among older Korean immigrants. The results of a study conducted in 2012 in Los Angeles County, 
in which 220 first generation Korean immigrants aged 65 years or older participated, showed that older Korean immigrants with severe neuroticism and higher levels of hopelessness were more likely to experience higher levels of depression.

Beck's [5] cognitive theory of depression also posits that irrational negative thoughts, stressors, and incidents that create a feeling of being helpless to change a situation contribute to the emotional and cognitive frame of depression. Beck and his colleagues [6] also suggested that a person with depression will remain stable and will not have suicidal tendencies unless they develop irrational beliefs and feelings of hopelessness.

Hopelessness is defined as one's tendency to possess a negative point of view or a set of negative expectations for the future [7]. Individuals who have feelings of hopelessness are often characterized by possessing a negative view about the future and believe that nothing will turn out right for them, that they will never succeed at what they try to do, that their important goals can never be attained, and that their worst problems will never be solved [8]. In addition to depression, several studies have suggested that hopelessness may play an important role in suicidal thoughts, suicide attempts, completed suicide, low life satisfaction, and some psychiatric disorders for both normal and clinical populations [9-12]. Studies have also shown that higher levels of hopelessness are associated with undesirable health problems, such as cardiovascular diseases and high blood pressure $[13,14]$. Available evidence also suggests that hopelessness is a psychological construct with a major role in the relationship between suicide and depression [2,15-18]. Moreover, previous research has revealed that mortality rates are higher among those with high levels of hopelessness when compared to those with lower levels of hopelessness [19].

A number of studies, which have been conducted to estimate the prevalence of hopelessness in the general population, have suggest that among different age groups, hopelessness ranges from $1 \%$ to $56 \%$ (from mild to severe levels) [19-21]. Specifically, these studies demonstrated that hopelessness levels tend to increase with age, and among those who are 50 years or older, hopelessness prevalence ranges from $2 \%$ to $59 \%$ [19-21]. These diverse prevalence rates are more likely to be associated with the fact that studies usually used different assessment instruments, different cut-off points, different samples, various operational definitions of the hopelessness construct, and cultural differences. However, in order to have more information about precise estimates of prevalence in specific populations, there is still a need for evidence of prevalence rates of hopelessness in different samples.

Studies examining the correlates of hopelessness have focused on sociodemographic factors such as gender, socio-economic level, perceived health, ability to work, age, marital status, and profession [20-24]. Considering the negative effects of hopelessness levels on peoples' physical and mental health, the determination of hopelessness levels plays an important role in increasing well-being and also partly in preventing physical health problems in the elderly. Therefore, the aim of the study was to determine the prevalence of hopelessness in the elderly living in senior centers and with their families, and to determine the related risk factors. The specific research questions addressed in the present study are as follows:

1. What is the prevalence rate of hopelessness among the elderly with respect to gender and place of residence (living with family or in a nursing home)?

2. Is there a relationship between participants' sociodemographics and their levels of hopelessness?

3. What are the predictors of the levels of hopelessness among the elderly after controlling for place of residence (living with family or in a nursing home) in this study?

\section{Methods}

\subsection{Research Design}

This study used a correlational research design to examine the variables related to hopelessness among elderly Turkish people [25]. The dependent variable was hopelessness level, while the independent variables included gender, age, place of residence, and monthly income level. Although 
age and monthly income are generally measured as a continuous variable, we measured these variables as a categorical variable in this study.

\subsection{Participants}

The study participants consisted of elderly people in their 50s or over who lived in senior centers or with their families in a city in the central Black Sea region of Turkey. They were recruited using convenience sampling. Specifically, the researchers included their older relatives, acquaintances, and friends in the study sample. Then, they asked these people to help them to find elderly people who were able to complete the survey. At the same time, after obtaining formal permission from local authorities, elderly people living in a senior center in Samsun city were visited, and those who volunteered and met the study criteria were included in the study sample. The inclusion criteria were being 50 years old or older, being able to read and answer questionnaire items, and having no severe physical or mental illness (e.g., schizophrenia). These procedures continued until the necessary sample size was met for a medium effect size. Effect size was calculated using a medium effect size with a power of 0.80 for multiple regression analysis requiring a minimum sample size of 85 participants [26]. The participants included 51 females and 49 males. Half the sample lived in the senior center, while the other half lived with their families. There were 29 participants between the ages 50 and 59 , 34 participants between 60 and 69, and 37 were 70 or above. In terms of marital status, eight were single, 16 were divorced, 44 were widowed/widowers, and 32 were currently married. As for the income level variable, 54 of the participants had a monthly income of approximately $\$ 330$ or less (1000 TL or lower), while 46 had a monthly income of approximately \$331 or more (1001 TL or above) as of the date of the survey.

\subsection{Measures}

Personal Information Form. Participants were asked to give information about their gender, age, income, and place of residence on this form. Gender was measured by asking participants "What is your gender?". Participants answered this question indicating Male or Female. Age was measured by asking participants "What is your age?" Participants indicated their answer on a three-point scale: between ages 50 and 59, between 60 and 69, or 70 or above. Income was measured by asking "What is your income level?" Participants also indicated their income level using a three-point scale: \$330 or less, $\$ 331$ to $\$ 660$, or $\$ 661$ or more. Finally, participants reported their place of residence answering following question: “Where do you live?" Participants answered this question by indicating with my family or Nursing home.

Hopelessness. The hopelessness was measured using the Beck Hopelessness Scale (BHS). This scale, which is the most frequently employed measure of hopelessness among diverse populations, was developed by Beck et al. [17]. The BHS's adaptation into the Turkish language, validity, and reliability have been conducted by various researchers on different samples, including adults and the elderly [27,28]. The BHS has shown good psychometric properties, such as adequate construct, convergent and discriminant validity, internal consistency, and test-retest stability across these studies [27,28]. The scale consists of 20 items, each of which the respondents are asked to assess by choosing Yes or No. Nine items in the scale are reverse coded. These reverse coded items are recoded before summing the items, and the total scores of the scale range from 0 to 20 . Higher scores are associated with higher levels of hopelessness. BHS scores can also be classified based on an individual's hopelessness scores. According to Beck and Steer [8], scores between 0 to 3 indicate normal levels, 4 to 8 indicate mild levels, 9 to 14 indicate moderate levels, and 15 or above indicate severe hopelessness levels. The internal consistency coefficient of the BHS (Kuder-Richardson-20) was calculated to be 0.87. An example item from the BHS is "I look forward to the future with hope and enthusiasm." 


\subsection{Procedure}

Data collection and analysis were conducted between February and June of 2016. The questionnaire was administered to those aged 50 or above who lived in close proximity to the researchers, and those who lived in senior centers after the relevant permission was obtained. The administration of the questionnaire took place in quiet places where the respondents would be as far from noise as possible and would not be affected negatively by people's moods or other distractions. The participants were also informed that their participation was voluntary, their answers would be kept confidential and would not be used for any other purpose other than study goals, and they could withdraw from the study at any time without any consequences. Completion of the questionnaire required approximately $15 \mathrm{~min}$.

\subsection{Statistical Analysis}

All statistical analyses were performed with IBM SPSS Statistic for Windows, Version 23. Preliminary data analyses were conducted to screen the data as suggested by Tabachnick and Fidell [29]. The data was examined for accuracy, frequency distribution, missing values, outliers, item-total correlation of the BHS, and assumptions of statistical analysis. All values in the dataset were within the expected range. No missing values and outliers were found [29]. When the participants were grouped based on their marital status, there were not enough participants in the single, divorced, and married subgroups to perform statistical analyses, so these groups were collapsed into two categories: Widowed/Widower or not. Additionally, the monthly income level variable was separated into two groups for statistical analysis: $\$ 330$ or less and $\$ 331$ or more.

The item-total correlation of the BHS scores was also examined, and consistent with previous studies $[24,30]$, some items of the BHS $(3,11,12)$ were found to have low item-total correlation below the often-suggested threshold value (0.30; Field [31]). Thus, the correlation and regression analysis were conducted again after removing these items, and similar findings were obtained, with the exception of small differences in correlation and beta coefficients. Moreover, when these three problematic items were excluded from the scale, we found only a marginal improvement in reliability, such that the internal consistency coefficient of the scale without these three items was measured as 0.90 , while it was 0.87 before the items were removed. Additionally, the correlation between the 17 -item version of the BHS and the original 20-item BHS was very strong $(r=0.984)$. Thus, all items in the BHS were used in order to compare the current study's results with those of previous studies. The statistical analysis conducted using excluded items can be obtained from the first researcher upon request.

Statistical analyses were performed in three stages. First, by using the classification suggested by Beck and Steer [8], the hopelessness levels of the elderly were reported in frequency and percentages based on gender, place of residence, and total. Chi-square tests were performed to examine the relationship between hopelessness levels and gender and between hopelessness levels and place of residence. A series of post hoc $z$-tests was also used to compare column proportions using Bonferroni adjustment when chi-square tests were significant.

Pearson correlation analysis was employed to examine the associations among all relevant study variables in the second stage. The categorical variables, which had more than two subgroups in both the correlation and regression analysis, were coded as dummy variables and then included in the analysis. The independent variables with low explanatory power were not included in the regression analysis. For instance, the gender variable that was not correlated with the hopelessness scores in this study was not included in the regression analysis. Hierarchical multiple regression was calculated to assess the ability of age, marital status, and monthly income to predict levels of hopelessness after controlling for place of residence. The researchers determined the independent variables' entry order into the regression equation taking into account theory, previous research, as well as logic or practicality in hierarchical multiple regression analysis [32]. Although there is limited evidence, previous research has shown that people living in nursing homes are more likely to have higher hopelessness levels than people living with their families [23]. Thus, place of residence entered the regression equation in Step 1, and other correlates of hopelessness entered in Step 2. The assumptions of correlation 
and multiple regression analysis were also checked. In order to examine the normality of regression errors, we performed a Kolmogorov-Smirnov normality test for residuals for final model and found that residuals were normally distributed $(D(100)=0.06, p>0.05)$. Breusch-Pagan (BP) and Konker test results also suggested that heteroscedasticity is not present or error variances are all equal in final model $\left(\mathrm{BP} \chi^{2}(5)=3.29, p>0.05\right.$; Konker $\left.\chi^{2}(5)=4.61, p>0.05\right)$. Finally, inspection of condition index suggested that all condition index below the recommended threshold value of 15 [32]. Thus, multicollinearity does not appear to be a problem in these analyses. Because of the relative scarcity of previous research examining to hopelessness differences between nursing home and living with family elderly, we also replicated to regression analysis using four different regression techniques including Enter, Backward, Forward, and Stepwise methods. The results of these regression analyses also showed the same significant predictors of hopelessness scores in hierarchical multiple regression analysis (Step 2) with small differences in beta coefficients. Data used in this study is available from Open Science Framework (osf.io/2b3yu). A statistical significance level of two-tailed $p=0.05$ has been used in all statistical analyses.

\section{Results}

Table 1 presents the hopelessness levels of the participants with respect to gender and Table 2 presents the hopelessness levels of the participants with respect to place of residence. As seen in Table 1, 19\% of the participants had normal levels of hopelessness, $22 \%$ had mild levels, $37 \%$ had moderate levels, and $22 \%$ had severe levels. The majority of both males and females had a moderate level of hopelessness. A series of chi-square tests was used to determine whether the hopelessness levels were related to gender and place of residence. Chi-square test results indicated that hopelessness levels were not related to gender $\left(\chi^{2}(3, N=100)=1.31, p>0.05\right.$, Cramer's $\left.V=0.12\right)$.

Table 1. Hopelessness levels of the participants with respect to sex.

\begin{tabular}{ccccccc}
\hline \multirow{2}{*}{ Level } & \multicolumn{2}{c}{ Female } & \multicolumn{2}{c}{ Male } & \multicolumn{2}{c}{ Total } \\
\cline { 2 - 7 } & $\boldsymbol{n}$ & $\mathbf{\%}$ & $\boldsymbol{n}$ & $\mathbf{\%}$ & $\boldsymbol{n}$ & $\mathbf{\%}$ \\
\hline Normal & 8 & 15.7 & 11 & 22.4 & 19 & 19 \\
Mild & 12 & 23.5 & 10 & 20.4 & 22 & 22 \\
Moderate & 18 & 35.2 & 19 & 38.8 & 37 & 37 \\
Severe & 13 & 25.5 & 9 & 18.4 & 22 & 22 \\
Total & 51 & 100 & 49 & 100 & 100 & 100 \\
\hline
\end{tabular}

Table 2. Hopelessness levels of the participants with respect to residence.

\begin{tabular}{ccccccc}
\hline \multirow{2}{*}{ Level } & \multicolumn{2}{c}{ Senior Center } & \multicolumn{2}{c}{ Living with Family } & \multicolumn{2}{c}{ Total } \\
\cline { 2 - 7 } & $\boldsymbol{n}$ & $\mathbf{\%}$ & $\boldsymbol{n}$ & $\mathbf{\%}$ & $\boldsymbol{n}$ & $\mathbf{\%}$ \\
\hline Normal & $4 \mathrm{a}$ & 8 & $15_{\mathrm{b}}$ & 30 & 19 & 19 \\
Mild & 7 & 14 & 15 & 30 & 22 & 22 \\
Moderate & 19 & 38 & 18 & 36 & 37 & 37 \\
Severe & $20 \mathrm{a}$ & 40 & $2_{\mathrm{b}}$ & 4 & 22 & 22 \\
Total & 51 & 100 & 49 & 100 & 100 & 100 \\
\hline
\end{tabular}

Note: Each frequency number denotes a and $\mathrm{b}$ subset of residence categories whose column proportions differ significantly from each other at the 0.05 level.

However, hopelessness levels were found to be related to place of residence $\left(\chi^{2}(3, N=100)=24.03\right.$, $p<0.05$, Cramer's $V=0.49)$. In order to determine the source of difference between proportions with respect to place of residence, we performed a series of $z$-tests to compare column proportions using Bonferroni adjustment. The results of the $z$-tests revealed that people with normal hopelessness levels were more likely to live with their families and people with severe hopelessness levels were more likely to live in senior centers. Other column proportions did not differ significantly from each other. 
Table 3 shows the correlations among variables of interest in the study. As seen in Table 2, hopelessness scores were not correlated with gender $(r=-0.10, p>0.05)$ or an age range between 60-69 $(r=0.07, p>0.05)$. On the other hand, hopelessness scores were weakly but positively correlated with being 70 years old or older $(r=0.26, p<0.01)$. Additionally, hopelessness scores were negatively and moderately correlated with place of residence $(r=-0.49, p<0.01)$, and positively associated with being widowed/a widower $(r=0.48, p<0.01)$. In other words, consistent with previous studies and the above-mentioned chi-square test results, people living in senior centers had significantly higher hopelessness scores than people living with their families. Finally, the hopelessness scores were highly and positively associated with having a monthly income of $\$ 330$ or less $(r=0.53, p<0.01)$.

Table 3. The correlations among the study variables.

\begin{tabular}{|c|c|c|c|c|c|c|c|c|}
\hline & 1 & 2 & 3 & 4 & 5 & 6 & 7 & 8 \\
\hline \multicolumn{9}{|l|}{ 1. BHS } \\
\hline 2. Gender & -0.10 & & & & & & & \\
\hline 3. Place of residence & $-0.49^{* *}$ & 0.10 & & & & & & \\
\hline 4. Widowed/Widower & $0.48 * *$ & $0.22 *$ & $-0.28 * *$ & & & & & \\
\hline 5. Age 50-59 & $-0.34^{* *}$ & 0.04 & $0.42^{* *}$ & -0.12 & & & & \\
\hline 6. Age 60-69 & 0.07 & -0.03 & -0.08 & 0.04 & $-0.46^{* *}$ & & & \\
\hline 7. Age 70+ & $0.26^{* *}$ & -0.01 & $-0.31^{* *}$ & 0.07 & $-0.49^{* *}$ & $-0.55^{* *}$ & & \\
\hline 8. Monthly income & $-0.53 * *$ & 0.14 & $0.56^{* *}$ & $-0.45^{* *}$ & $0.34^{* *}$ & -0.07 & $-0.25 *$ & \\
\hline Mean & 9.49 & 0.49 & 0.50 & 0.44 & 0.29 & 0.34 & 0.37 & 0.46 \\
\hline Standard Deviation & 5.30 & 0.50 & 0.50 & 0.50 & 0.46 & 0.48 & 0.49 & 0.50 \\
\hline
\end{tabular}

Note. $p<0.05^{*}, p<0.01^{* *}$. The variables between 4 and 7 were included in the analysis as dummy variables. BHS: Beck Hopelessness Scale; Gender: 0: Female, 1: Male; Place of Residence: 0: Nursing home, 1: Living with Family; Monthly income: 0: \$330 or less, 1: \$331 or more. Correlations between BHS scores and other variables also represent point biserial correlations. Correlations from gender variable to monthly income variable also represent phi coefficients.

A hierarchical multiple regression analysis was used to determine the covariate variables of hopelessness after controlling for the place of residence. The results are presented in Table 4.

Table 4. Results of the hierarchical regression analysis.

\begin{tabular}{|c|c|c|c|c|c|c|c|c|c|c|c|c|}
\hline Variable & \multicolumn{5}{|c|}{ Step 1} & \multicolumn{7}{|c|}{ Step 2} \\
\hline Constant & 12.06 & 0.66 & & 18.32 & $0.001 * *$ & 1.00 & 10.39 & 1.06 & & 9.82 & $0.001 * *$ & 1.00 \\
\hline Widowed/Widower & & & & & & & 3.21 & 0.94 & 0.30 & 3.41 & $0.001^{* *}$ & 2.26 \\
\hline Age 50-59 & & & & & & & -1.33 & 1.12 & -0.11 & -1.19 & 0.238 & 3.27 \\
\hline Age 70+ & & & & & & & 0.66 & 1.00 & 0.06 & 0.66 & 0.508 & 3.99 \\
\hline$R^{2}$ & 0.24 & & & & & & 0.42 & & & & & \\
\hline $\operatorname{Adj} R^{2}$ & 0.23 & & & & & & 0.39 & & & & & \\
\hline SE Est. & 4.66 & & & & & & 4.16 & & & & & \\
\hline$F\left(d f_{\mathrm{n}}, d f_{\mathrm{d}}\right)$ & 1,98 & & & & & & 5,94 & & & & & \\
\hline
\end{tabular}

Note. Age 60-69 used as reference category, C.I.: Condition Index, $p<0.05^{*}, p<0.001 * *$.

As seen in Table 4, the place of residence variable, which was included in the analysis at the first stage, significantly associated with the hopelessness scores $\left(F(1,98)=30.47, p<0.001, R=0.49, R^{2}=0.24\right.$, $R^{2}$ adj $=0.23$ ). In other words, consistent with our expectations and previous studies, the elderly living in nursing homes are more likely to have higher levels of hopelessness when compared to those living with their families. Moreover, age, marital status, and monthly income, which were included in the regression analysis at the second stage, were found to contribute to the model significantly $\left(F(5,94)=13.46, p<0.001, R=0.65, R^{2}=0.42, R^{2}\right.$ adj $\left.=0.39\right)$, and $R^{2}$ changes were also significant $\left(\Delta R^{2}=0.18\right)$. Closer examination of variables of interest in the final model demonstrated that being widowed/a widower $(\beta=0.30, t(94)=3.41, p<0.001)$ and having a monthly income of $\$ 330$ or less 
$(\beta=-0.22, t(94)=-2.07, p<0.05)$ positively associated with hopelessness scores after controlling for place of residence. The model had a high effect size.

\section{Discussion}

The purpose of this study was to examine the prevalence of hopelessness and associated factors in Turkish elderly people living with their families or in nursing homes. Using the cut-off scores suggested by Beck and Steer [8], the results revealed that $81 \%$ of the elderly, or approximately eight out of ten, have hopelessness ranging from mild to severe levels and severe hopelessness is more prevalent among elderly people living in nursing homes. Moreover, no gender differences were found in terms of the severity of hopelessness among the elderly. Our results are consistent with previous research indicating that hopelessness is common among the elderly [20,21]. However, our results differ from the findings of the study conducted by Dong and Chang [19] who found that about $41 \%$ of the older adults experience feelings of hopelessness. These differences may be related to two factors. First, Dong and Chang [19] conducted their study with Chinese people living in the US, while the current study was applied to elderly Turkish people living in nursing homes and with their families. Previous research has shown that individuals living in nursing homes have higher levels of depression, hopelessness, and suicidal thoughts than the elderly living with their families [23]. Although nursing homes provide necessary basic needs, health care, and individual and group activities to alleviate loneliness and increase happiness among the elderly such as going to cinema, going on a picnic, reading a book or chatting with a friend, in Turkey, nursing homes are not often preferred. In traditional Turkish society, elder persons are cared for by their children if needed, and nursing homes are often regarded as a last resort. If elderly individuals live in a senior center, it is usually due to the absence of a close relative. In other words, the elderly who have weak social support networks prefer or must find accommodation at nursing homes. The fact that the elderly from nursing homes were included in the study may be one possible reason for the high levels of hopelessness observed in this study. The second difference is that this study and that conducted by Hamzaoğlu et al. [21] used the 20-item Beck Hopelessness Scale. However, Dong and Chang [19] used a shortened version of the Beck Hopelessness Scale including only seven items. Thus, the different scales may have resulted in different outcomes.

Another finding of the study suggests that the marital status-being a widow or widower-is positively correlated with hopelessness. In other words, widows or widowers tend to be at a higher risk of experiencing hopelessness. These findings are consistent with the results of the study conducted by Ron [23] with the elderly living in senior centers and with their families in Israel, which indicated that widowed individuals tend to have a higher level of hopelessness than married individuals. Efklides, Kalaitzidou, and Chankin [33] also found that marital status correlated negatively with life satisfaction and subjective well-being, that is, married participants gave higher reports of life satisfaction and subjective well-being than participants living alone. According to a recent survey by the Turkish Statistical Institute [34], the most important source of happiness among the elderly was their families. Thus, one possible explanation of this finding may be that with the loss of the spouse, individuals may experience lower life satisfaction and more stress and loneliness and may become more pessimistic about the future.

The results of this study suggests that low income is positively associated with hopelessness. These findings are also consistent with previous research results indicating that low socio-economic status is a risk factor in the general population for hopelessness [20,21,35]. In a meta-analysis study, Pinquart and Sörensen [36] found that elderly individuals with higher socioeconomic status (especially higher income), better social integration (especially high quality social ties), and higher competence (both the basic competence needed to maintain an independent life and expanded competence to fill the day with meaningful activities) reported greater life satisfaction, higher self-esteem, and greater happiness. Income level plays a critical role in meeting the individual's needs and wants. People with low income are more likely to have difficulties in meeting their basic needs and buying the things they want. Thus, they may develop a more pessimistic point of view about the future. 
Finally, the limitations of this study should be addressed. First, this study was conducted with a limited number of elderly people living in the central Black Sea region of Turkey. Although we had adequate power to detect prevalence and predictors of hopelessness, our sample size was relatively small and mainly from a specific region of Turkey. Moreover, we also used convenience sampling that may limit generalizability of results to population of interest. Thus, the external validity of this study is low. Future research should be conducted with a larger and more varied sample. Second, this was a cross-sectional study, which provides up-to-date information about the studied sample; however, cause and effect relationships between the findings cannot be established. It can only give us an idea about whether it can be a risk or protective factor. Thus, future studies should make use of a longitudinal research design. Third, the data was collected from the elderly through the use of a self-report questionnaire. Self-report scales may result in a number of common method biases, such as social desirability [37]. However, in this study, the researchers attempted to prevent this bias by assuring participants that their information and identity would be kept completely confidential [37]. However, in further studies, these variables could be investigated by collecting information from different sources (e.g., close friends).

\section{Conclusions}

The prevalence and correlates that can influence hopelessness in the Turkish elderly people were examined in this study, and the results suggest that the elderly who are widows or widowers, have low income levels, and live in nursing homes are more likely to have higher levels of hopelessness. These findings have some practical implications for prevention and intervention efforts toward the elderly regarding the hopelessness problem. First, in order to gain a more comprehensive understanding of the correlates of hopelessness, researchers should take into account some sociodemographic factors including place of residence, marital status, and income level. Second, mental health professionals trying to identify at-risk elders should particularly consult with the elderly who are widows or widowers, have low income levels, and live in nursing homes in an attempt to increase hope among these populations. Considering the fact that hopelessness levels are also correlated with suicidal thoughts, depression, and adverse health conditions, the mental health professionals who aim to increase the well-being of the elderly should also conduct screening studies to determine hopelessness levels of their clients. Intervention and prevention programs should target elderly women and men equally. However, researchers can develop prevention and intervention programs by targeting elderly widows or widowers, those have low income levels, and those live in nursing homes. Finally, home visits and different social activities could be employed in order to determine and increase the quality of life and conditions of the elderly.

Author Contributions: E.Ş. participated in designing the data collection instruments, performed data collection and analyses. E.Ş. and N.T. drafted the manuscript. N.T., E.E., and C.G. performed data collection, participated in designing the instruments, reviewed and revised the manuscript. E.Ş. and E.E. conceptualized and designed the study, designed the data collection instruments, and coordinated and supervised data collection. All authors critically reviewed the manuscript. All authors approved the final manuscript as submitted.

Acknowledgments: Portions of earlier drafts of this paper were presented in October 2016 at the 7th World Conference on Learning, Teaching and Leadership in Budapest, Hungary.

Conflicts of Interest: The authors declare no conflict of interest.

\section{References}

1. Andreas, S.; Schulz, H.; Volkert, J.; Dehoust, M.; Sehner, S.; Suling, A.; Ausín, B.; Canuto, A.; Crawford, M.; Ronch, C.D.; et al. Prevalence of mental disorders in elderly people: The European MentDis_ICF65+ study. Br. J. Psychiatry 2017, 210, 125-131. [CrossRef] [PubMed]

2. Sharma, K.; Gupta, A.; Sharma, R.C.; Mahajan, N.; Mahajan, A.; Sharma, D.; Mazta, S.R. Prevalence and risk factors for depression in elderly North Indians. J. Geriatr. Ment. Health 2016, 3, 158-163. 
3. Assari, S.; Lankarani, M.M. Depressive symptoms are associated with more hopelessness among White than Black older adults. Front. Public Health 2016, 4, 82. [CrossRef] [PubMed]

4. Kim, B.J.; Linton, K.; Cho, S.; Ha, J.-H. The relationship between neuroticism, hopelessness, and depression in older Korean Immigrants. PLoS ONE 2016, 11, e0145520. [CrossRef] [PubMed]

5. Beck, A.T. Depression: Clinical, Experimental, and Theoretical Aspects; Harper and Row: New York, NY, USA, 1967.

6. Beck, A.T.; Kovacs, M.; Weissman, A. Hopelessness and suicidal behavior: An overview. JAMA 1975, 234, 1146-1149. [CrossRef] [PubMed]

7. Perczel-Forintos, D.; Sallai, J.; Rózsa, S. Adaptation of the Beck Hopelessness Scale in Hungary. Psihologijske Teme 2010, 19, 307-321.

8. Beck, A.T.; Steer, R.A. Manual for the Beck Hopelessness Scale; Psychological Corporation: San Antonio, TX, USA, 1988.

9. Cheung, Y.B.; Law, C.K.; Chan, B.; Liu, K.Y.; Yip, P.S.F. Suicidal ideation and suicidal attempts in a population-based study of Chinese people: Risk attributable to hopelessness, depression, and social factors. J. Affect. Disord. 2006, 90, 193-199. [CrossRef] [PubMed]

10. Kuo, W.-H.; Gallo, J.J.; Eaton, W.W. Hopelessness, depression, substance disorder, and suicidality: A 13-year community-based study. Soc. Psychiatry Psychiatr. Epidemiol. 2004, 39, 497-501. [CrossRef] [PubMed]

11. Mystakidou, K.; Tsilika, E.; Parpa, E.; Pathiaki, M.; Galanos, A.; Vlahos, L. The relationship between quality of life and levels of hopelessness and depression in palliative care. Depress. Anxiety 2008, 25, 730-736. [CrossRef] [PubMed]

12. Szanto, K.; Reynolds, C.F., III; Conwell, Y.; Begley, A.E.; Houck, P. High levels of hopelessness persist in geriatric patients with remitted depression and a history of attempted suicide. J. Am. Geriatr. Soc. 1998, 46, 1401-1406. [CrossRef] [PubMed]

13. Anda, R.; Williamson, D.; Jones, D.; Macera, C.; Eaker, E.; Glassman, A.; Marks, J. Depressed affect, hopelessness, and the risk of ischemic heart disease in a cohort of U.S. adults. Epidemiol. Camb. Mass 1993, 4, 285-294. [CrossRef]

14. Everson, S.A.; Kaplan, G.A.; Goldberg, D.E.; Salonen, J.T. Hypertension incidence is predicted by high levels of hopelessness in Finnish men. Hypertension 2000, 35, 561-567. [CrossRef] [PubMed]

15. Abramson, L.Y.; Alloy, L.B.; Hogan, M.E.; Whitehouse, W.G.; Cornette, M.; Akhavan, S.; Chiara, A. Suicidality and cognitive vulnerability to depression among college students: A prospective study. J. Adolesc. 1998, 21, 473-487. [CrossRef] [PubMed]

16. Beck, A.T.; Brown, G.; Steer, R.A. Prediction of eventual suicide in psychiatric inpatients by clinical ratings of hopelessness. J. Consult. Clin. Psychol. 1989, 57, 309-310. [CrossRef] [PubMed]

17. Beck, A.T.; Weissman, A.; Lester, D.; Trexler, L. The measurement of pessimism: The Hopelessness Scale. J. Consult. Clin. Psychol. 1974, 42, 861-865. [CrossRef] [PubMed]

18. Dyer, J.A.T.; Kreitman, N. Hopelessness, depression and suicidal intent in parasuicide. Br. J. Psychiatry 1984, 144, 127-133. [CrossRef] [PubMed]

19. Dong, X.; Chang, E.S. Understanding hopelessness among community-dwelling Chinese older adults in the Greater Chicago Area. J. Gerontol. Geriatr. Res. 2014, 3, 193. [CrossRef]

20. Haatainen, K.; Tanskanen, A.; Kylmä, J.; Honkalampi, K.; Koivumaa-Honkanen, H.; Hintikka, J.; Viinamäki, H. Factors associated with hopelessness: A population study. Int. J. Soc. Psychiatry 2004, 50, 142-152. [CrossRef] [PubMed]

21. Hamzaoglu, O.; Ozkan, O.; Ulusoy, M.; Gokdogan, F. The prevalence of hopelessness among adults: Disability and other related factors. Int. J. Psychiatry Med. 2010, 40, 77-91. [CrossRef] [PubMed]

22. Greene, S.M. Levels of measured hopelessness in the general population. Br. J. Clin. Psychol. 1981, 20, 11-14. [CrossRef]

23. Ron, P. Depression, hopelessness, and suicidal ideation among the elderly. J. Gerontol. Soc. Work 2004, 43, 97-116. [CrossRef]

24. Tanaka, E.; Sakamoto, S.; Ono, Y.; Fujihara, S.; Kitamura, T. Hopelessness in a community population: Factorial structure and psychosocial correlates. J. Soc. Psychol. 1998, 138, 581-590. [CrossRef] [PubMed]

25. Cohen, L.; Manion, L.; Morrison, K. Research Methods in Education; Routledge: London, UK, 2007; ISBN 978-0-415-37410-1. 
26. Faul, F.; Erdfelder, E.; Lang, A.-G.; Buchner, A. G*Power 3: A flexible statistical power analysis program for the social, behavioral, and biomedical sciences. Behav. Res. Methods 2007, 39, 175-191. [CrossRef] [PubMed]

27. Durak, A.; Palabıyıkoğlu, R. Beck Umutsuzluk Ölçeği geçerlilik çalışması (The validity of Beck Hopelessness Scale). Kriz Dergisi 1993, 2, 311-319.

28. Seber, G.; Dilbaz, N.; Kaptanoğlu, C.; Tekin, D. Umutsuzluk ölçeği: Geçerlilik ve güvenirliği (The Hopelessness Scale: Validity and reliability). Kriz Dergisi 1993, 1, 139-142.

29. Tabachnick, B.G.; Fidell, L.S. Using Multivariate Statistics, 6th ed.; Pearson Education: Harlow, UK, 2014; ISBN 1-299-95716-1.

30. Steed, L. Further validity and reliability evidence for Beck Hopelessness Scale scores in a nonclinical sample. Educ. Psychol. Meas. 2001, 61, 303-316. [CrossRef]

31. Field, A. Discovering Statistics Using IBM SPSS Statistics, 4th ed.; Sage: Los Angeles, CA, USA, 2013.

32. Ho, R. Handbook of Univariate and Multivariate Data Analysis with IBM SPSS, 2nd ed.; Chapman and Hall/CRC: Boca Raton, FL, USA; New York, NY, USA, 2013; ISBN 978-1-4665-7009-2.

33. Efklides, A.; Kalaitzidou, M.; Chankin, G. Subjective quality of life in old age in Greece: The effect of demographic factors, emotional state and adaptation to aging. Eur. Psychol. 2003, 8, 178-191. [CrossRef]

34. Turkish Statistical Institute. The Database of an Address Based Population Registry System: Population According to Age Group and Gender. Available online: http:/ / www.turkstat.gov.tr/PreHaberBultenleri.do? $\mathrm{id}=21520$ (accessed on 13 December 2017).

35. Soares, J.J.F.; Macassa, G.; Grossi, G.; Viitasara, E. Psychosocial correlates of hopelessness among men. Cogn. Behav. Ther. 2008, 37, 50-61. [CrossRef] [PubMed]

36. Pinquart, M.; Sörensen, S. Influences of socioeconomic status, social network, and competence on subjective well-being in later life: A meta-analysis. Psychol. Aging 2000, 15, 187-224. [CrossRef] [PubMed]

37. Podsakoff, P.M.; MacKenzie, S.B.; Lee, J.-Y.; Podsakoff, N.P. Common method biases in behavioral research: A critical review of the literature and recommended remedies. J. Appl. Psychol. 2003, 88, 879-903. [CrossRef] [PubMed]

(C) 2018 by the authors. Licensee MDPI, Basel, Switzerland. This article is an open access article distributed under the terms and conditions of the Creative Commons Attribution (CC BY) license (http:/ / creativecommons.org/licenses/by/4.0/). 